\title{
Low concentrations of morphine enhanced the neuroglia-like differentiation
}

\author{
Zhaleh $\mathrm{H}^{1}$, Azadbakht $\mathrm{M}^{2}$, Bidmeshki Pour $\mathrm{A}^{2}$ \\ Substance Abuse Prevention Research Center, Kermanshah University of Medical Sciences, \\ Kermanshah, Iran. hossain_jale@yahoo.com
}

\section{ABSTRACT}

AIM: The present study was undertaken to evaluate the effects of different concentrations of morphine in chronic manner on neuroglial differentiation in PC12 cells.

METHODS: PC12 cells were cultured in RPMI 1640 culture medium including $0.02 \%$ bovine serum albumin together with different concentrations of morphine for 12 days. Cytotoxicity was performed by lactate dehydrogenase assay. Cell death was performed by PI/Hoechst staining assay. Neuroglial differentiation was performed by Nestin, Tuj-1, MAP-2, S-100 and GFAP Immunocytochemistry assay.

RESULTS: Data showed that morphine either at low or high concentration activated opioid receptors, which resulted in a decrease of cytotoxicity and cell death and induction of Nestin, Tuj-1, MAP-2, Neurofilament-M (NF-M), GFAP and S-100 protein expression as compared in treated cells with the control (untreated cells) $(\mathrm{p}<005)$.

CONCLUSION: It can be concluded that low concentrations of morphine in chronic manner stimulate the neuroglial-like differentiation by activating protein expression and survival-promoting signaling in PC12 cells with opioid receptor-dependent mechanism (Fig. 8, Ref. 36). Text in PDF www.elis.sk. KEY WORDS: morphine, naltrexone, neuroglial differentiation, PC12 cell.

\section{Introduction}

Morphine is an effective pain-relieving drug and can affect neurotransmitter release, reduction of intracellular cAMP and apoptosis in neuronal cells $(1,2)$.

Morphine binds to $\mathrm{Mu}$ receptor and modulates survival (3-5), apoptosis (6), cell growth (7), proliferation (7-13), and viability (9) of neural and tumoral cells (14-16). Morphine has an effective role in the development of CNS, neuritogenesis, and cell differentiation of neuroglial cells (18-22). Further, concerning neuritogenesis, chronic morphine has been found to exert two opposite effects that are concentration-dependent. Morphine, at $1 \mathrm{mM}$ concentration, inhibited neurite elongation in PC12 cells, cerebellar granule neurons, cerebellar neuroblasts, and embryonic dorsal root ganglion neurons with naloxone-dependent mechanism whereas, at 1pM, enhanced neurite elongation of PC12 cells, cultured rat spinal cord, cerebral cortical neurons with naloxone-independent mechanism (22-25).

${ }^{1}$ Substance Abuse Prevention Research Center, Kermanshah University of Medical Sciences, Kermanshah, Iran, and ${ }^{2}$ Department of Biology, Faculty of Science, Razi University, Kermanshah, Iran

Address for correspondence: $\mathrm{H}$. Zhaleh, Dr, PhD, Substance Abuse Prevention Research Center, Kermanshah University of Medical Sciences, Kermanshah, Iran.

Acknowledgements: This work was partially supported by the Biology Department of Razi University and Substance Abuse Prevention Research Center of Kermanshah University of Medical Sciences (Kermanshah, Iran).
This study was undertaken to determine whether chronic exposure of morphine stimulates neuronal differentiation in PC12 cells and whether that action dependent on the mu-opioid receptor.

\section{Materials and methods}

\section{Cell culture}

PC12 cells were grown in RPMI 1640 culture media (Gibco), supplemented with $10 \%$ fetal bovine serum (FBS, Gibco), $1 \%$ non-essential amino acid (NEAA; Sigma), 2 mM L-glutamine (Sigma), $100 \mathrm{IU} / \mathrm{ml}$ penicillin (Sigma), and $100 \mu \mathrm{g} / \mathrm{ml}$ streptomycin (Sigma) in 10-cm tissue culture dishes. The cultures were incubated at $37{ }^{\circ} \mathrm{C}$ in $5 \% \mathrm{CO}_{2}$ medium was replaced every 2 days. While cell cultures reached 70 to $80 \%$ confluency, they were trypsinated using trypsin-EDTA $0.25 \%$ (Sigma) and were subcultured at a density of $1 \times 10^{4}$ cells/well in 24 -well culture plates.

\section{Morphine treatment}

One day after plating the cells, cells were washed with phosphate buffer saline (PBS), $\mathrm{pH}$ : 7.4. There were two groups: group I; no preincubation with naltrexone hydrochloride (Sigma) (without naltrexone) and group II; preincubation with $100 \mathrm{nM}$ naltrexone. There were six treatments in each group. PC12 cells were cultured in RPMI 1640 culture medium containing $0.02 \%$ bovine serum albumin (BSA; Sigma) together with different concentrations of morphine sulfate (Temad, Iran). The treatments were $1 \times 10^{-12} \mathrm{M}$ morphine (treatment 1 ), $1 \times 10^{-10} \mathrm{M}$ morphine (treatment 2), $1 \times 10^{-8} \mathrm{M}$ morphine (treatment 3 ), $1 \times 10^{-6}$ 


\section{1-277}

$\mathrm{M}$ morphine (treatment 4 ) and $1 \times 10^{-4}$ $\mathrm{M}$ morphine (treatment 5) and culture media alone (treatment 6) for 12 days. The cells were placed in the incubator at $37{ }^{\circ} \mathrm{C}$ with $5 \% \mathrm{CO}_{2}$.

\section{Cell cytotoxicity measurement}

Cell cytotoxicity was quantified by measuring the release of lactate dehydrogenase (LDH) from damaged or destroyed cells into the media. Cytotoxicity was measured with LDH Cytotoxicity Detection Kit (Roche, Germany). Cells were plated in 24 well culture plates with $1 \times 10^{4}$ cells $/ \mathrm{mL}$ densities for $12 \mathrm{~h}$. Then, cells were cultured by differentiation medium for $24 \mathrm{~h}$. The colorimetry of LDH activity was measured by calculating the absorbance of samples at $492 \mathrm{~nm}$ using a plate reader (EL800; USA). All experiments were replicated independently at least 3 times. Within each experiment, we replicated each condition 4 times.

\section{Quantification of cell death incidence}

Hoechst / PI nuclear staining was carried out as previously described (26). Briefly, cells were plated in 24 wells culture plates with $1 \times 10^{4}$ cells $/ \mathrm{mL}$ density for $12 \mathrm{~h}$. Cells were then cultured in different treatment media for certain time. Then, cells were incubated for $15 \mathrm{~min}$ at $37{ }^{\circ} \mathrm{C}$ with Hoechst 33342 dye (10 $\mathrm{mg} / \mathrm{ml}$ in PBS), washed twice in PBS PI $(50 \mathrm{mg} / \mathrm{ml}$ in PBS$)$ added just before microscopy. Cells were visualized using an inverted-florescence microscope (Olympus IX-71, Japan). All experiments were independently replicated at least 3 times. Within each experiment, we replicated each condition 4 times.

\section{Immunofluorescence microscopy}

Cells were grown in 24 wells of cell culture plate in different treatment media. Then, cells were fixed in $4 \%$ Paraformaldehyde for $20 \mathrm{~min}$ at room temperature and permeabilized with $0.1 \%$ TritonX-100/PBS for $5 \mathrm{~min}$. Then, cells were incubated in PBS containing $0.5 \%$ bovine serum albumin and $0.1 \%$ Tween 20 for 30 min to reduce nonspecific binding, followed by overnight incubation at $4{ }^{\circ} \mathrm{C}$ with the following rabbit polyclonal Abs: Nestin (1:50; Chemicon); MAP-2 (1:50; Santa Cruz Biotechnology); Tuj-1 (1:40; Sigma), NF-M (1:1000; Chemicon, Inc, Temecula, CA), S-100
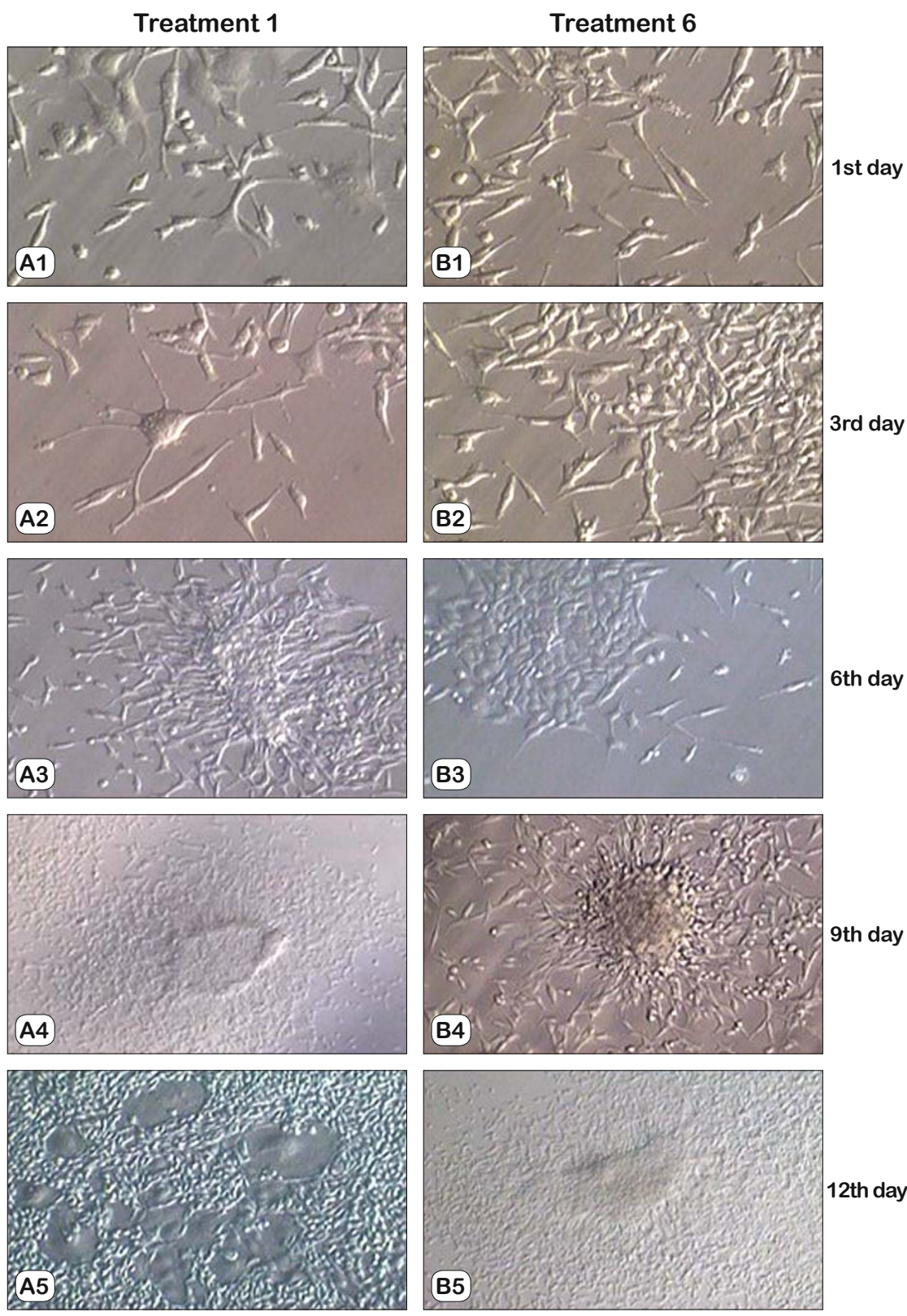

12th day

Fig. 1. Effects of different concentration of morphine on morphology of the cells. Interestingly, morphine exhibited a neuron like morphology with a short neurite outgrowth in PC12 cells at 12 days in culture. In the group $I$, Morphine at low concentration (treatment 2, $A_{1,2}$ ) compared to the group II formed a neuroglial morphology in PC12 cells at 3 days in culture. In the group I, Morphine in all treatment, especially in treatment 5 , compared to the group II were likely to be postsynaptic. In this treatment, morphine resulted in colonization with a disperse neuroglial network in cultured cells at 6 days in culture $\left(B_{2-5}\right) . A_{1}-A_{5}: 10^{-10} M$ morphine; $B_{1}-B_{5}: 10^{-4} M$ morphine; $A_{1}, B_{1}$ : after 1 day culture; $A_{2}, B_{2}:$ after 3 days culture; $A_{3}, B_{3}:$ after 6 days culture; $A_{4}, B_{4}$ : after 9 days culture; $A_{5}, B_{5}$ : after 12 days culture.

(1:5000; Dako) and GFAP (1:64; Sigma). After washing, Alexa Fluor 488-conjugated (green) secondary Abs (1:500) was applied for $1 \mathrm{~h}$ at room temperature. The slides were treated with anti-fade reagent (Molecular Probes, Inc) and examined for immunofluorescence with the Olympus microscope. 


\section{Results}

Interestingly, morphine exhibited a neuron-like morphology with a short neurite outgrowth in PC12 cells at 12 days in culture (Fig. 1). In the group I, Morphine at low concentration (treatments 1 and 2) compared to the group II formed a neuroglial morphology in PC12 cells at 3 days in culture (Fig. 1). In the group I, at low concentration, morphine result in a heavy glial-like morphology with an expansion cell body and few neuron-like morphologies with a short neurite outgrowth in the culture dish. In the group I, Morphine in all treatment, especially in the treatment 4 and 5, compared to the group II, was likely to be postsynaptic. In these treatments, morphine resulted in colonization with disperse neuroglial network in cultured cells at 6 days in culture (Fig. 1).

Some studies suggest that morphine induces apoptosis of glial cells and neurons (27), whereas others suggest that morphine

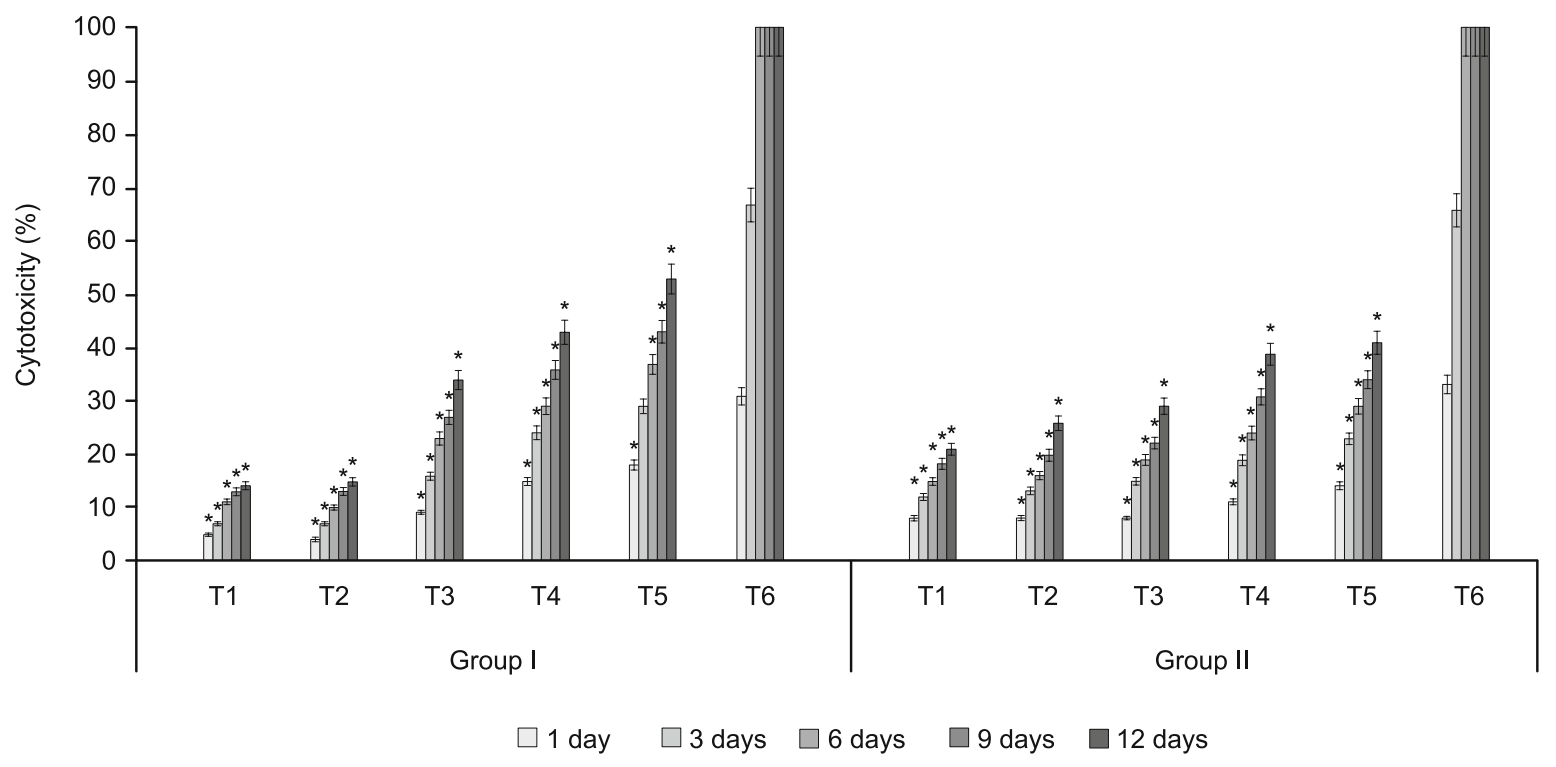

Fig. 2. Effects of different concentration of morphine on cell cytotoxicity in cells. All data represented by mean \pm SEM $(p<0.05)$.

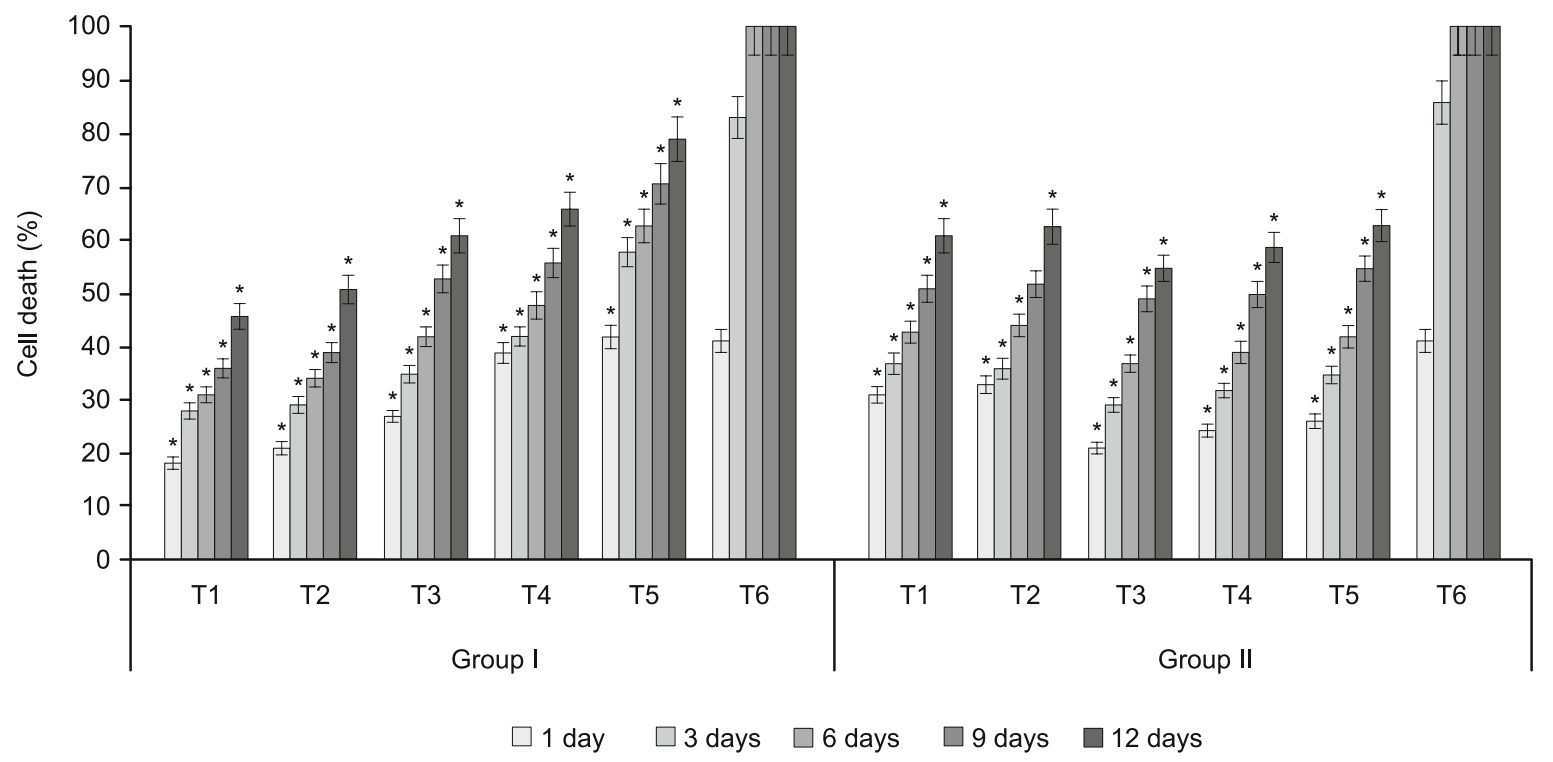

Fig. 3. effects of different concentration of morphine on cell death in cells. All data represented as the mean $\pm \operatorname{SEM}(\mathbf{p}<0.05)$. 

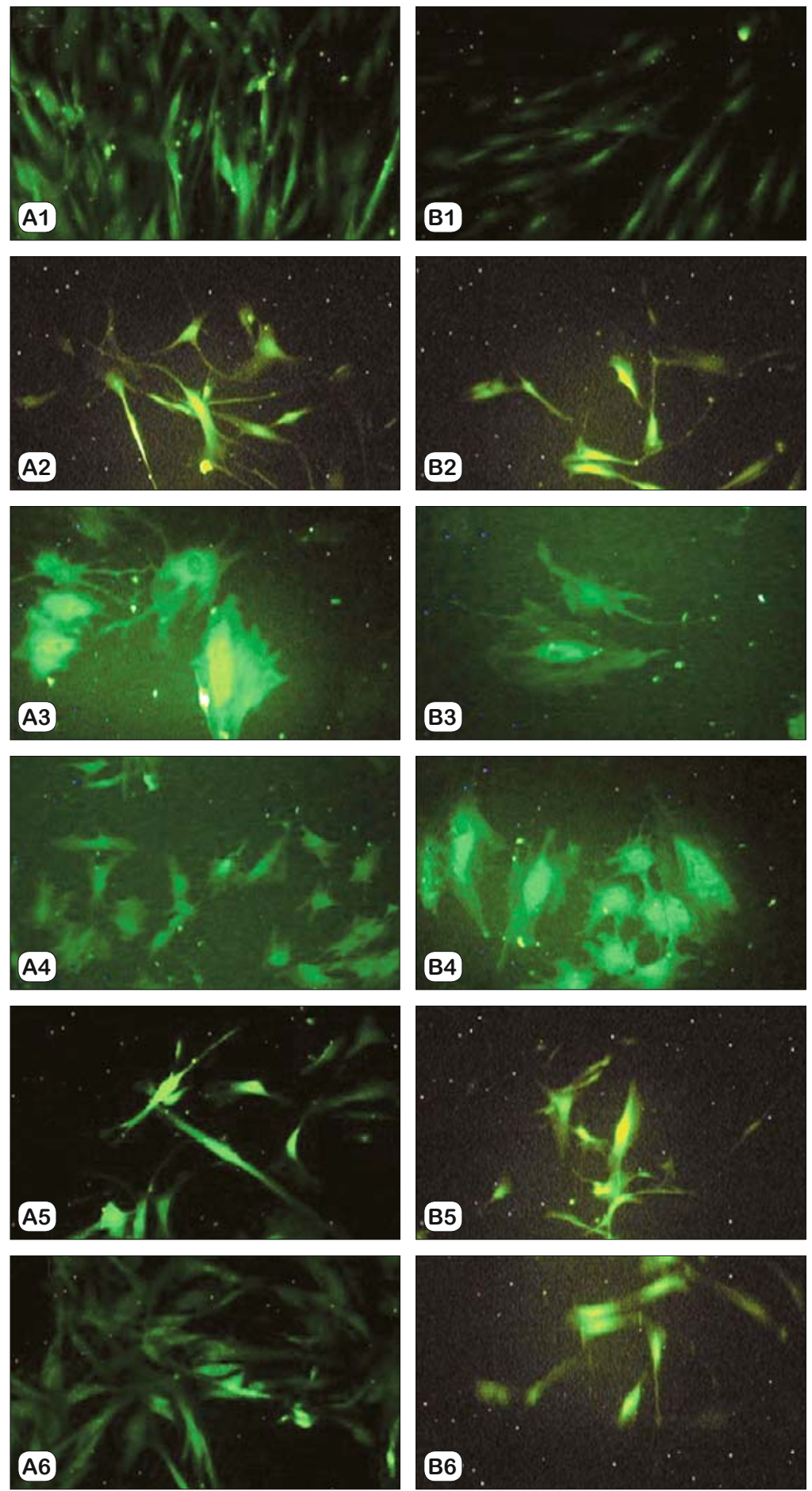

Fig. 4. Immunocytochemistry microscopic detection of protein marker expression in Morphine-induced PC12 cells after 6 days culture. A1-A6: $10^{-10} \mathrm{M}$ morphine; B1-B6: $10^{-4} M$ morphine; $A_{1}, B_{1}$ : Nestin; $A_{2}, B_{2}$ : NF-M; A3,B3: S-100; A4,B4: GFAP; A5,B5: MAP-2; A6,B6: Tuj-1. Magnitude is x400.

protects neurons from cell death (28). Morphine-induced changes in spines could be caused by loss of cells due to cell death. To check this possibility, we used double staining of PI and Hoechst (PI/H) together with cytotoxicity assay by LDH activity to detect cell death and cell cytotoxicity in two groups for 12 days cultured PC12 cells (Figs 2 and 3). At first, cells were exposed to different concentrations of morphine, then, cell cytotoxicity was measured by LDH assay at 1, 3, 6, 9 and 12 days after the exposure. In the group I, the results of this experiment showed that in treatments 1-3 the percentage of cell cytotoxicity was decreased compared to the treatments 4,5 and 6 . While in the group II, exposure of the cells to the different concentrations of morphine reversed the effect of cell cytotoxicity (Fig. 2). To induce cell death as positive controls, we treated such cultured cells with staurosporine $(1 \mu \mathrm{M})$ for $6 \mathrm{~h}$. In the first day, about $\approx 92 \%$ of staurosporine-treated cells were apoptotic (Fig. 2, compared to the untreated). In contrast, as in untreated cells, the nuclei of morphine-treated cells were smooth, and such cells had little PI/H staining (Fig. 4). In the group $\mathrm{I}$, in treatments $1-3$ compared to staurosporine and untreated cells, the percentage of cell death was decreased $(p<0.05)$ (Fig. 3). In the group II compared to the group I, in these treatments, the percentage of cell death were increased $(p<0.05)$. On the other hand, in the group I compared to staurosporine treated and untreated cells, in treatments 4 and 5 the percentage of cell death was decreased $(p<0.05)$. In the group II compared to the group I, in treatments 4 and 5 the percentage of cell death was decreased $(\mathrm{p}<0.05)$. To further examine the possible loss of cells, cultured cells were treated with morphine for 6-12 days, and studied. In the two groups, untreated cell bodies of neurons were not visually identified. The percentage of cell death and cell cytotoxicity for untreated cells was $100 \%$, and they were completely dead in culture dishes (Figs 2 and 3). In the group I, the percentage of cell cytotoxicity and cell death for morphine-treated neurons in the treatments 1-5 compared to the untreated cells was decreased $(p<0.05)$. These results indicate that the morphineinduced changes in cells were likely to be largely caused by suppression of cell death and cytotoxicity, and these acts of morphine depended on opioid receptors.

The state of differentiation of morphine-induced PC12 cells was characterized by immunocytochemistry at 6 and 12 days after the exposure. For this purpose, PC12 cells were maintained under serum deprivation-induced self-renewal conditions, or they were differentiated in the presence of a different concentration of morphine.

For the immunocytochemistry experiments, cultures were stained with nestin (a neural progenitor marker), MAP-2, Tuj-1, NF-M (mature neural markers), and S-100 and GFAP (glial pro- 


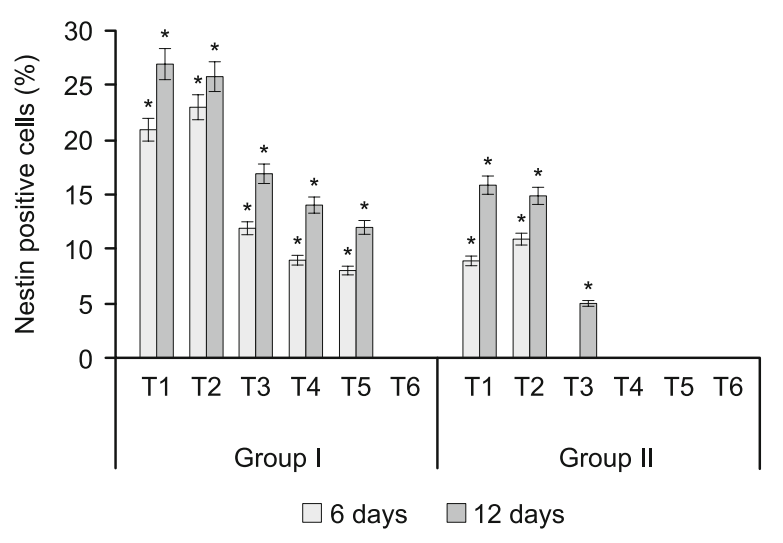

Fig. 5. The density of Nestin positive cells in morphine-induced PC12 cells after 12 days culture. All data represented as the mean \pm SEM $(\mathbf{p}<0.05)$.

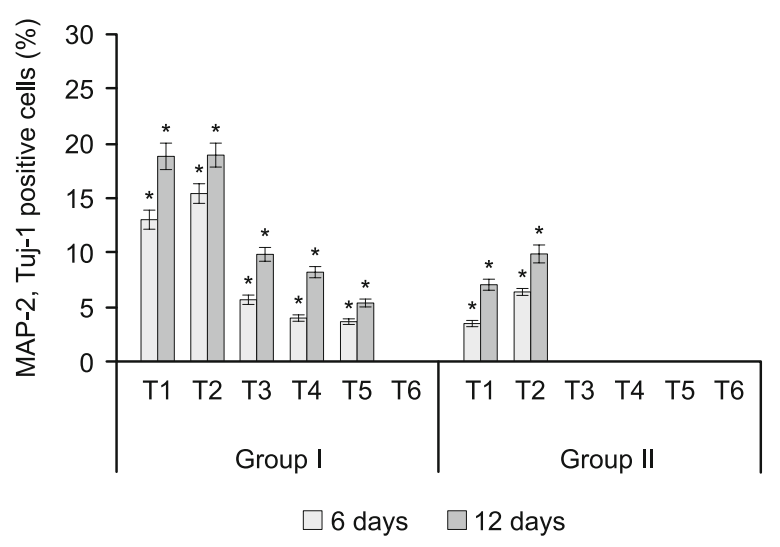

Fig. 6. The density of Tuj-1 and MAP-2 positive cells in morphine-induced PC12 cells after 12 days culture. All data represented as the mean \pm SEM $(\mathbf{p}<\mathbf{0 . 0 5})$.

genitor marker) Antibodies (Fig. 4). To further examine possible differentiated cells, cultured cells were treated with different concentration of morphine in two groups for 6 and 12 days, fixed, stained and the percentage of stained cells was mounted. The cell bodies of stained cells were visually identified, and the number of stained cells on total cells (stained and unstained cells) in 100 were counted.

In the group I, there were nestin-stained cells among the undifferentiated PC12 cells, whereas morphine-induced PC12 cells showed few staining with nestin (Fig. 5). In treatments 1 and 2 compared to the untreated cells (treatment 6 ), the density of nestinstained cells was increased $(p<005)$. In treatments $3-5$, there was no significant difference compared to the treatment 6 .

In the group I, there was no Tuj-1, MAP-2 and NF-M-stained cells among the undifferentiated PC12 cells, whereas morphineinduced PC12 cells showed a good staining with antibodies (Figs 6 and 7). In treatments 1 and 2 compared to the treatments 3-6, the density of Tuj-1, MAP-2 and NF-M-stained cells was increased

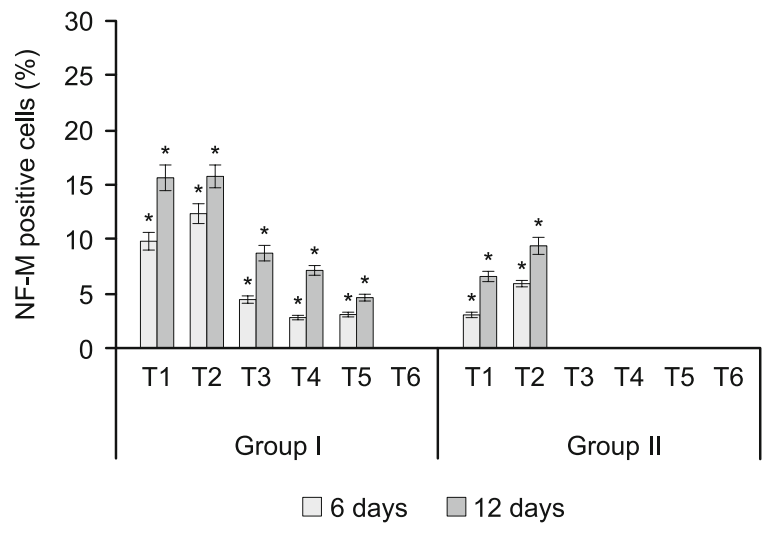

Fig. 7. The density of NF-M positive cells in morphine-induced PC12 cells after 12 days culture. All data represented as the mean \pm SEM $(\mathbf{p}<\mathbf{0 . 0 5})$.

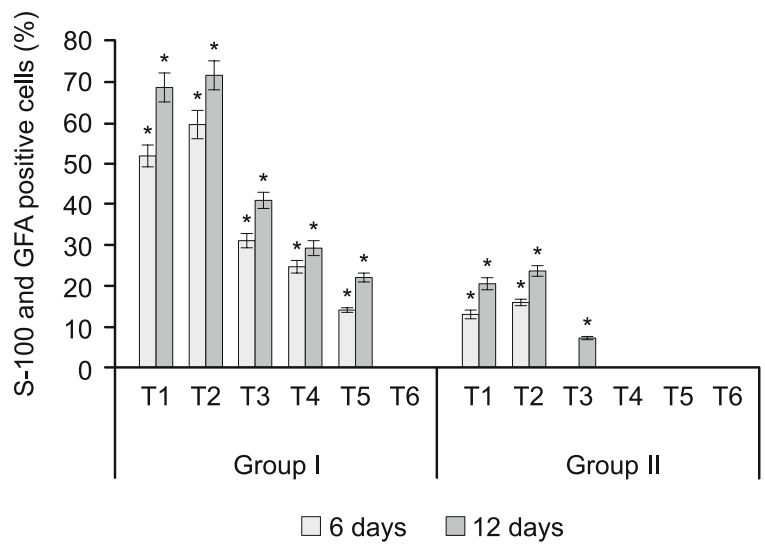

Fig. 8. The density of S-100 and GFAP positive cells in morphine-induced PC12 cells after 12 days culture. All data represented as the mean \pm SEM $(p<0.05)$.

$(\mathrm{p}<0.05)$. In treatments $3-5$ they were significantly increased compared to the treatment $6(\mathrm{p}<0.05)$.

In the group I, there was no S-100 and GFAP-stained cells among the undifferentiated $\mathrm{PC} 12$ cells, whereas morphine-induced PC12 cells showed a heavy staining with antibodies (Fig. 8). In treatments 1 and 2 compared to the treatments $3-6$, the density of S-100 and GFAP-stained cells was increased $(p<0.05)$. In treatments $3-5$ they were significantly increased compared to the treatment $6(\mathrm{p}<0.05)$. In the group II, preincubated cells by naltrexone resulted in reversed concentration effects of morphine on the differentiation of cells $(\mathrm{p}<0.05)$.

In the group I, at low concentration, morphine resulted in a heavy glial-like or S-100 and GFAP-positive cell with an expansion of cell body and few neuron-like morphologies or Tuj-1, MAP-2 and NF-M positive cell with a short neurite outgrowth in culture dish compared to the group II and other treatments $(p<0.05)$. In the group I, Morphine in treatment 4 and 5, compared to the group II was likely to be postsynaptic and resulted in a coloniza- 
tion with a disperse neuroglial network (GFAP positive cells were connected to MAP-2 positive cells) in cultured cells at 6 and 12 days in culture (Fig. 1).

\section{Discussion}

In the present study, we evaluated the effect of different concentrations of morphine on cell differentiation in PC12 cells. Meanwhile, we concluded that chronic exposure to low and high concentrations of morphine led to neuroglial differentiation with a short neurite elongation in PC12 cells with the opioid-dependent mechanism. Our data revealed that administration of low concentration of morphine increased cell differentiation morphology, especially the glial form, and neuroglial zone colonization in PC12 cells (Fig. 1). Indeed, chronic treatment with morphine or naltrexone profoundly altered the function of cell differentiation (Fig. 5). Our data revealed that administration of low and high concentrations of morphine could lead to cell death and cell cytotoxicity in PC12 cells.

Our results were confirmed by enhancing and suppressing the cell differentiation by $\mathrm{pM}$ and $\mathrm{mM}$ concentrations of morphine in PC12 cells in the previous study (22). The inhibitory effect of pretreating with $100 \mathrm{nM}$ naltrexone on neurite elongation suggests that this effect was induced by opioid receptor signal transduction. Serum deprivation decreased the density and increased cell death and cell cytotoxicity of PC12 cells. Morphine treatment alone increased the cell viability and decreased cell death and cell cytotoxicity of PC12 cells. The simple explanation is that these two changes are mediated through the activation of the opioid receptor. In addition, chronic treatment with morphine profoundly altered the morphology of PC12 cells. Previous in vivo studies showed that chronic morphine administration decreased the density of spines in rats in comparison to the untreated control rats, whereas naltrexone increased the density of spines (29-31). Morphine, at chronic exposure, can cause changes of neuron synaptic plasticity, neurogenesis and neuronal differentiation (32-35). Opioid with activation of its receptors had an important effects on the nervous system. For example, it has been confirmed that opioids affected the neuronal differentiation and some of them like cocaine can induce neuronal differentiation (25). The previous study showed that in the presence of NGF, chronic low concentrations of morphine exposure enhanced neurite elongation of spinal and cortical neurons via a naloxone-independent mechanism in a chronic manner (22, 25 ). Although, morphine at $1 \mu \mathrm{M}$ concentration inhibits staurosporine-induced apoptosis by enhanced Hsp70 protein expression, its effects on neurite outgrowth at acute exposure is not clear (36).

However, the morphine-induced increase in the density of neurite-like structure can be caused by the enhancement of the growth of new spines. Our results indicate that opioids mainly affect the induction and stabilization of the formation and maturation of neuroglial network in cultured cells (Fig. 1). Furthermore, these morphological changes are accompanied by functional changes consistent with such morphological changes (Figs 1 and 5).

In addition, chronic treatment using a low concentration of morphine profoundly altered the glial-neuronal protein marker expression in PC12 cells. Data showed that low concentrations of morphine increased the density of S-100, GFAP, MAP-2, NF-M, and Tuj-1 positive cells in PC12 cells in comparison to the untreated control cells, whereas naltrexone decreased the density of stained cells (Fig. 5).

The latter might have a role in the pathological basis for drug addiction. In addition to acting on cell viability and cell differentiation in PC12 cells, morphine may act directly on synapses between neuroglial differentiated cells as shown in this study. The interaction between these two distinct mechanisms is not yet known.

\section{References}

1. Goldstein A. Binding selectivity profiles for ligands of multiple receptor types: focus on opioid receptors. Trends Pharmacol Sci 1987; 8 (5): 456-500

2. Williams JT, Christie MJ, Manzoni O. Cellular and Synaptic Adaptations Mediating Opioid Dependence. American Physiological Society Physiological Reviews2001; 81 (17): 299-303.

3. Goldstein A, Naidu A. Multiple opioid receptor: ligand selectivity profiles and binding site signatures. Mol Pharmacol 1989; 36 (4): 265-271.

4. Benyamin R, Trescot AM, Datta S, Buenaventura R, Adlaka R, Sehgal N, Glaser SE et al. Opioid Complications and Side Effects. Pain Physician Opioid Special Issue 2008; 11 (13): 105-109.

5. Schwindinger WF, Robishaw JD. Heterotrimeric G-protein betagammadimers in growth and differentiation. Oncogene 2001; 20 (6): 1653-1659.

6. Meriney SD, Gray DB, Pilar G. Morphine-induced delay of normal cell death in the avian ciliary ganglion. Science 1985; 228 (6): 1451-1458.

7. Gupta K, Kshirsagar S, Chang L, Schwartz R, Law PY, Yee D, Hebbel RP. Morphine stimulates angiogenesis by activating proangiogenic and survival-promoting signaling and promotes breast tumor growth. Cancer Res 2002; 63 (11): 4491-4495.

8. Singhal PC, Sharma P, Sanwal V, Prasad A, Kapasi A, Ranjan R, Franki $\mathbf{N}$ et al. Morphine modulates proliferation of kidney fibroblasts. Kidney Int 1998; 53 (4): 350-354.

9. Persson AI, Thorlin T, Bull C, Eriksson PS. Opioid-induced proliferation through the MAPK pathway in cultures of adult hippocampal progenitors. Mol Cell Neurosci 2003, 23 (5): 360-364.

10. Moon TD. The effect of opiates upon prostatic carcinoma cell growth. Biochem Biophys Res Commun 1988; 153 (12): 722-726.

11. Ni X, Lin BC, Song CY, Wang CH. Dynorphin A enhances mitogeninduced proliferative response and interleukin-2 production of rat splenocytes Neuropeptides. Neurosci Lett 1999; 33 (5): 137-142.

12. Law PY, Bergsbaken C. Properties of delta opioid receptor in neuroblastoma NS20Y: receptor activation and neuroblastoma proliferation. J Pharmacol Exp Ther 1995; 272 (3): 322-327.

13. Law PY, McGinn TM, Campbell KM, Erickson LE, Loh HH. Agonist activation of delta-opioid receptor but not mu-opioid receptor potentiates fetal calf serum or tyrosine kinase receptor-mediated cell proliferation in a cell-line-specific manner. Mol Pharmacol 1997; 51 (8): 152-157.

14. Hedin KE, Bell MP, Huntoon CJ, Karnitz LM, McKean DJ. Gi proteins use a novel beta gamma- and Ras-independent pathway to activate extracellular signal-regulated kinase and mobilize AP-1 transcription factors in Jurkat T lymphocytes. J Biol Chem 1999; 274 (6): 19992-19999. 
15. Kam AY, Chan AS, Wong YH. Phosphatidylinositol-3 kinase is distinctively required for micro-, but not kappa-opioid receptor-induced activation of c-Jun N-terminal kinase. J Neurochem 2004; 89 (6): 391-398.

16. Narita M, Ohnishi O, Nemoto M, Yajima Y, Suzuki T. Implications of phosphoinositide 3-kinase in the mu- and delta-opioid receptor-mediated supraspinal antinociception in the mouse. Neuroscience 2002, 113 (5): 647-652.

17. Kim MS, Cheong YP, So HS, Lee KM, Kim TY, Oh J, Chung YT et al. Protective effects of morphine in peroxynitrite-induced apoptosis of primary rat neonatal astrocytes: potential involvement of $\mathrm{G}$ protein and phosphatidylinositol 3-kinase (PI3 kinase). Biochem Pharmacol 2001; 61 (4): 779-784.

18. Eisch AJ, Barro M, Schad, CA, Self DW, Nestler EJ. Opiates inhibit neurogenesis in the adult rat hippocampus. Proc Natl Acad Sci 2000; 97 (7): 7579-7584.

19. Hauser KF, McLaughlin PJ, Zagon IS. Endogenous opioids regulate dendritic growth and spine formation in developing rat brain. Brain Res 1987; 416 (6): 157-163.

20. Liu B, Qin L, Yan SN, Wilson BC, Liu Y, Hong JS. Femtomolar concentrations of dynorphins protect rat mesencephalic dopaminergic neurons against inflammatory damage. J Pharmacol Exp 2001; 298 (4): 1133-1137.

21. Sakaguchi M, Fujimori T, Satoh T, Satoh M, Takeuchi M, Matsumura E; Effects of opioids on neuronal survival in culture of embryonic chick dorsal root ganglion neurons. Neurosci Lett 1999; 262 (7): 17-21.

22. Tenconi B, Lesma E, Di Giulio AM, Gorio A. High opioid doses inhibit whereas low doses enhance neuritogenesis in PC12 cells. Dev Brain Res 1996; 94 (7): 175-181.

23. Hauser KF, Houdi AA, Turbek CS, Elde RP, Maxson W. Opioids intrinsically inhibits the genesis of mouse cerebellar granule neuron precursors in vitro: differential impact of mu and delta receptor activation on proliferation and neurite elongation. Eur J Neurosci 2000; 12 (4): 1281-1286.

24. Opanashuk LA, Hauser KF. Opposing actions of the EGF family and opioids: heparin binding-epidermal growth factor (HB-EGF) protects mouse cerebellar neuroblasts against the antiproliferative effect of morphine. Brain Res 1998; 804 (5): 87-92.

25. Brailoiu E, Hoard J, Brailoiu GC, Chi M, Godbolde R, Dun NJ. Ultra low concentrations of morphine increase neurite outgrowth in cultured rat spinal cord and cerebral cortical neurons. Neurosci Lett 2004; 365 (11): 10-15.
26. Yuan W, Guo J, Li X, Zou Z, Chen G, Sun J, Wang T et al. Hydrogen peroxide induces the activation of the phospholipase C-g1 survival pathway in PC12 cells: protective role in apoptosis. Acta Biochim Biophys Sin 2009; 41 (5): 625-629.

27. Ricalde AA, Hammer R P. Perinatal opiate treatment delays growth of cortical dendrites. Neurosci Lett 1990; 115 (6): 137-143.

28. Robinson TE, Gorny G, Savage VR, Kolb B. Widespread but regionally specific effects of experimenter- versus self-administered morphine on dendritic spines in the nucleus accumbens, hippocampus, and neocortex of adult rats. Synapse 2002; 46 (12): 271-278.

29. Hauser KF, McLaughlin PJ, Zagon IS. Endogenous opioid systems and the regulation of dendritic growth and spine formation. J Comp Neuro 1989; 1281 (8): 13-19.

30. Hu S, Sheng WS, Lokensgard JR, Peterson PK. Morphine induces apoptosis of human microglia and neurons. Neuropharmacology 2002; 42 (6): 829-236.

31. Iglesias M, Segura MF, Comella JX, Olmos G. Mu-opioid receptor activation prevents apoptosis following serum withdrawal in differentiated SH-SY5Y cells and cortical neurons via phosphatidylinositol 3-kinase. Neuropharmacology 2003; 44 (7): 482-287.

32. Moron JA, Abul-Husn NS, Rozenfeld R, Dolios G, Wang R, Devi LA. Morphine administration alters the profile of hippocampal postsynaptic density-associated proteins: a proteomics study focusing on endocytic proteins. Mol Cell Proteomics 2007; 6 (5): 29-34.

33. Besson JM, Lancet T. The neurobiology of pain. Phys Pain 1999; 353 (7): 1610-1615.

34. Van Ooyen A, Van Pelt J, Corner MA. Implications of activity-dependent neurite outgrowth for neuronal morphology and network development. Theor Biol 1995; 172 (): 63-69.

35. Connaughton JF, Finnegan LP, Schut J, Emich JP. Concepts in the management of the pregnant opiate addict. Addict Dis 1975; 2 (9): 21-29.

36. Chen Q, Cui JY, Zhang YLC. Prolonged morphine application modulates Bax and Hsp70 levels in primary rat neurons. Neurosci Lett 2008; 441 (8): 311-316.
Received December 7, 2019. Accepted January 31, 2020. 